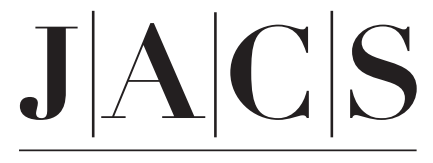

A R T I C L E S

Published on Web 02/13/2002

\title{
Stability and Aromaticity of the Cyclopenta-Fused Pyrene Congeners
}

\author{
Remco W. A. Havenith, ${ }^{\dagger, \ddagger}$ Haijun Jiao, ${ }^{\S}$ Leonardus W. Jenneskens, ${ }^{*, \dagger}$ \\ Joop H. van Lenthe, ${ }^{\ddagger}$ Martin Sarobe, ${ }^{\dagger}$ Paul von Rague Schleyer,,,$\|$ \\ Masahiro Kataoka, ${ }^{\perp}$ Atena Necula, ${ }^{\#}$ and Lawrence T. Scott ${ }^{\#}$ \\ Contribution from Department of Physical Organic Chemistry, Debye Institute, \\ Utrecht University, Padualaan 8, 3584 CH Utrecht, The Netherlands, Theoretical Chemistry \\ Group, Debye Institute, Utrecht University, Padualaan 8, 3584 CH Utrecht, The Netherlands, \\ Institut für Organische Chemie, Friedrich-Alexander Universität, Erlangen-Nürnberg, \\ Henkestrasse 42, D-91054 Erlangen, Germany, Computer Chemistry Annex, University of \\ Georgia, Athens, Georgia 30602-2525, Tohoku Pharmaceutical University, Komatsushima 4-4-1, \\ Aoba-ku, Sendai 981, Japan, and Department of Chemistry, Merkert Chemistry Center, \\ Boston College, Chestnut Hill, Massachusetts 02467-3860
}

Received June 25, 2001. Revised Manuscript Received November 9, 2001

\begin{abstract}
The aromaticity of all possible cyclopenta-fused pyrene congeners has been investigated at various levels of theory. On the basis of the calculated resonance energies and magnetic properties $\left(\delta^{1} \mathrm{H}\right.$ data, magnetic susceptibility anisotropies, and NICS values), the overall aromaticity of these compounds is found to decrease gradually with increasing number of externally fused five-membered rings. The relatively small differences $(<5 \mathrm{kcal} / \mathrm{mol})$ in thermodynamic stability of the isomeric dicyclopentapyrenes $\left(E_{\text {tot }}\right.$ : dicyclopenta[cd,fg]- > dicyclopenta[cd,jk]- > dicyclopenta[cd, $m n]$ pyrene), which differs from the aromaticity order based on the magnetic criteria (dicyclopenta[cd,mn]- > dicyclopenta[cd,fg]- > dicyclopenta[cd,jk]pyrene), is shown by model calculations to be dominated by $\sigma$-strain imposed on the pyrene skeleton by sequential cyclopenta-fusion. This is supported by the computed homodesmotic reaction energies and aromatic stabilization energy ( $\mathrm{ASE}_{\mathrm{isom}}$ ) from isodesmic aromatic-nonaromatic isomerization, and by the model calculations on "distorted" cyclopenta[cd]pyrenes. The elusive tetracyclopenta[cd,fg,jk, $m n]$ pyrene is computed to be bowl-shaped; its corresponding planar geometry is the transition state for bowl-bowl interconversion.
\end{abstract}

\section{Introduction}

Polycyclic aromatic hydrocarbons (PAH) containing unsaturated five-membered rings externally fused to six-membered ring perimeters (CP-PAHs) are important in several contexts. ${ }^{1} \mathrm{CP}$ PAHs have been identified as ubiquitous combustion effluents, and several representatives have been shown to possess considerable genotoxic activity. ${ }^{2}$ An example is cyclopenta[cd]pyrene (2), ${ }^{3}$ viz. the simplest externally cyclopenta-fused congener of pyrene (1), which is one of the most abundant nonalternant PAH combustion effluents (Figure 1). In addition,

* Corresponding author. Telephone: +31 302533128. Fax.: +31 302534533. E-mail: jennesk@chem.uu.nl.

Department of Physical Organic Chemistry, Debye Institute, Utrecht University.

$¥$ Theoretical Chemistry Group, Debye Institute, Utrecht University.

$\S$ Friedrich-Alexander Universität, Erlangen-Nürnberg.

"University of Georgia.

${ }^{\perp}$ Tohuku Pharmaceutical University.

\# Boston College.

(1) Harvey, R. G. Polycyclic Aromatic Hydrocarbons; Wiley-VCH: New York, 1997.

(2) For a review, see: Wiersum, U. E.; Jenneskens, L. W. In Gas-Phase Reactions in Organic Synthesis; Valleé, Y., Ed.; Gordon and Breach Science Publishers: Amsterdam, 1997; Chapter 3.

(3) Sarobe, M.; Snoeijer, J. D.; Wiersum, U. E.; Zwikker, J. W.; Jenneskens, L. W. J. Chem. Soc., Chem. Commun. 1994, 89-90 and references cited.

10.1021/ja011538n CCC: $\$ 22.00$ @ 2002 American Chemical Society
CP-PAHs are nonalternant PAHs and, thus, may exhibit unusual (photo)physical properties, e.g., anomalous fluorescence and high electron affinities. ${ }^{4,5}$

Recently the three isomeric dicyclopentapyrenes, i.e., dicyclopenta[cd,mn]- (3), dicyclopenta[cd,jk]- (4), and dicyclopenta$[c d, f g]$ pyrene $(\mathbf{5})$, were prepared by flash vacuum thermolysis (FVT) of the appropriate bis(1-chloroethenyl)pyrenes both in Utrecht $^{5,6,7}$ and in Boston. ${ }^{5,8,9}$ Although the incentive for their synthesis was the proposal that $\mathbf{3 - 5}$ might represent three previously unidentified combustion effluents, ${ }^{10}$ their availability also enabled a detailed study of their spectroscopic properties. Especially noteworthy are the striking variations in their ${ }^{1} \mathrm{H}$

(4) Gooijer, C.; Kozin, I.; Velthorst, N. H.; Sarobe, M.; Jenneskens, L. W.; Vlietstra, E. J. Spectrochim. Acta, Part A 1998, 54, 1443-1449 and references cited.

(5) Necula, A. Ph.D. Thesis, Boston College, Chestnut Hill, Massachusetts, USA, 1996. Sarobe, M. Ph.D. Thesis, Utrecht University, Utrecht, The Netherlands, 1998.

(6) Sarobe, M.; Flink, S.; Jenneskens, L. W.; van Poecke, B. L. A.; Zwikker, J. W. J. Chem. Soc., Chem. Commun. 1995, 2415-2416.

(7) Jenneskens, L. W.; Sarobe, M.; Zwikker, J. W. Pure Appl. Chem. 1996, 68, 219-224 and references cited.

(8) Scott, L. T.; Necula, A. J. Org. Chem. 1996, 61, 386-388.

(9) Scott, L. T. Pure Appl. Chem. 1996, 68, 291-300 and references cited

(10) Lafleur, A. L.; Howard, J. B.; Taghizadeh, K.; Plummer, E. F.; Scott, L. T.; Necula, A.; Swallow, K. C. J. Phys. Chem. 1996, 100, 17421-17428 and references cited. 

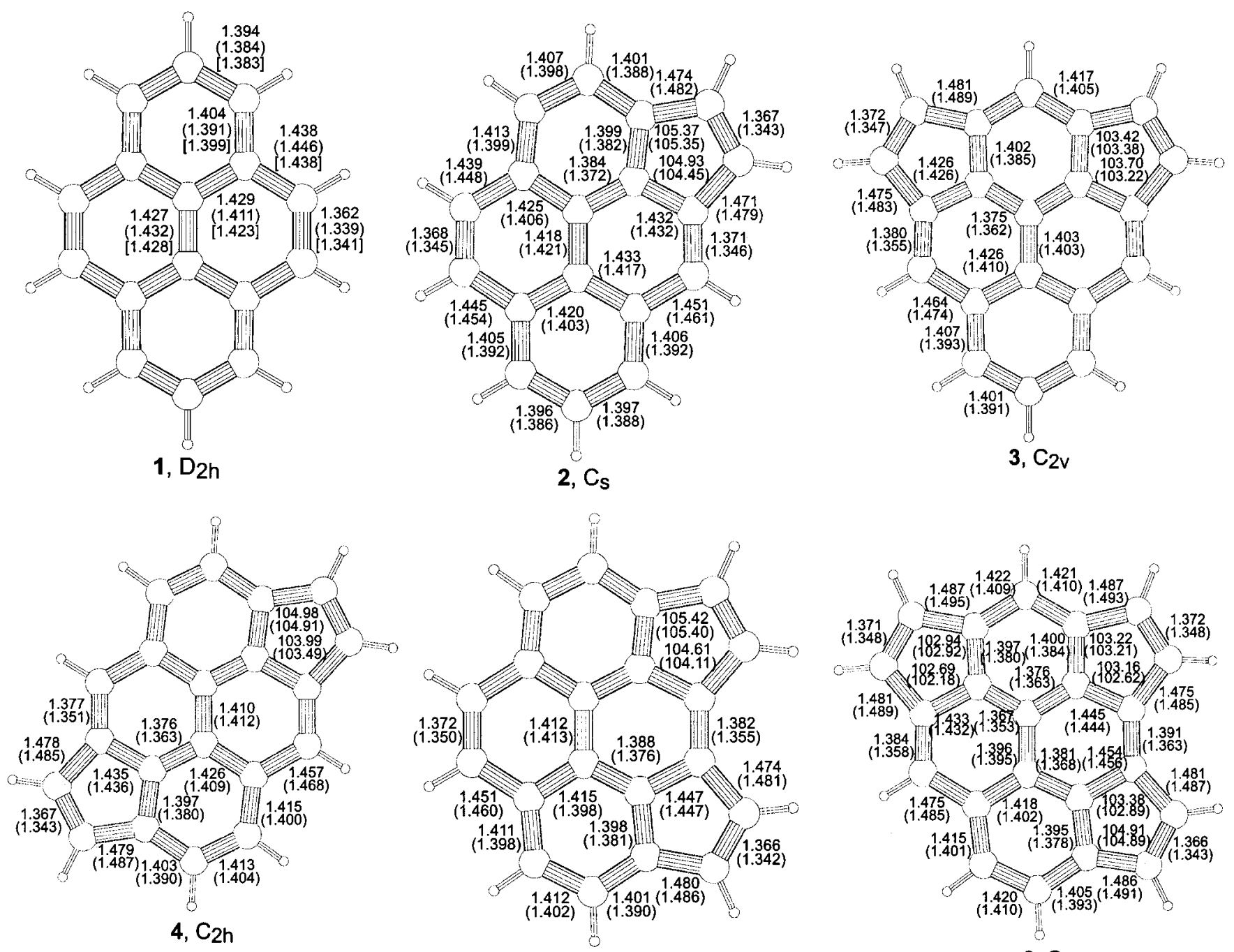

$5, \mathrm{C}_{2 \mathrm{v}}$

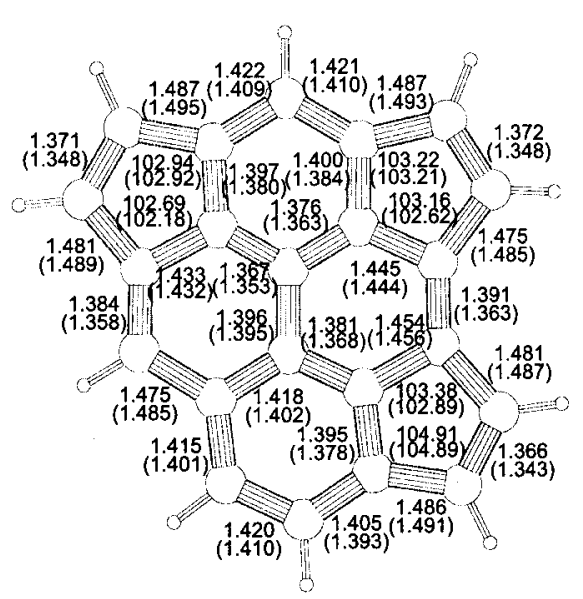

6, $C_{s}$
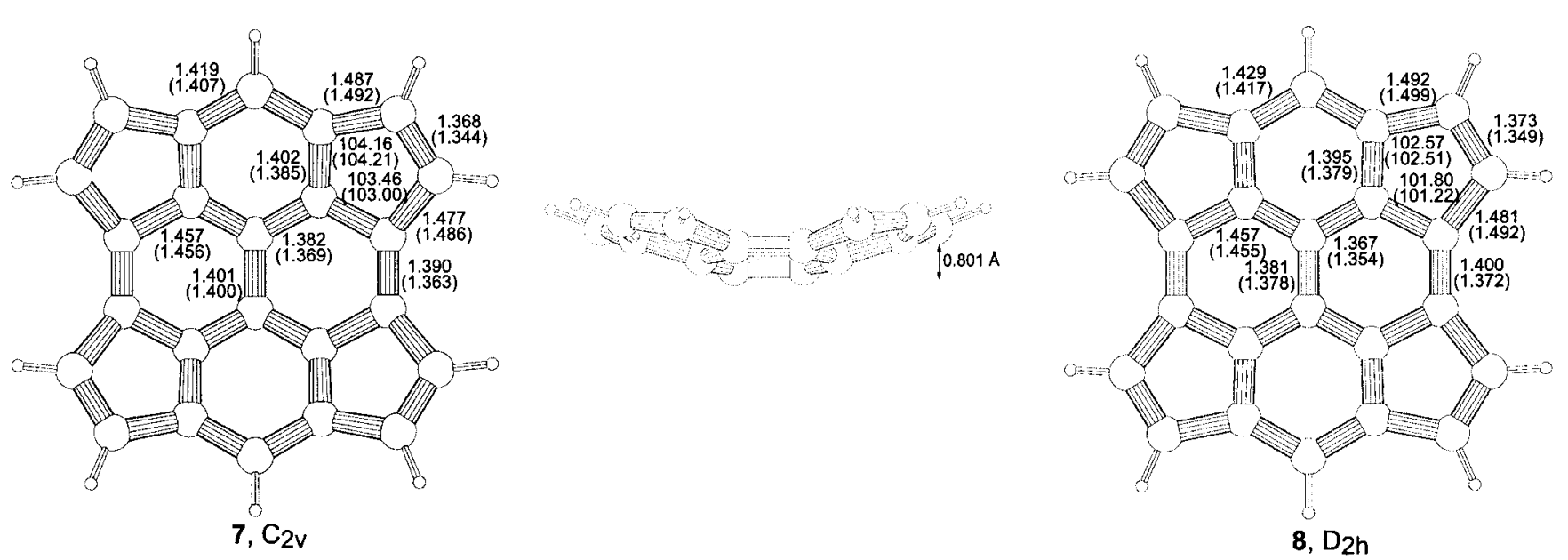

Figure 1. B3LYP/6-31G* (RHF/6-31G* in parentheses) bond lengths ( $\AA$ ) and bond angles (deg) of 1-8. For bowl-shaped 7 also a side view is presented. See Supporting Information for Cartesian coordinates of the optimized geometries of 1-8. Single-crystal X-ray data of $\mathbf{1}$ are presented in square brackets. ${ }^{31}$

NMR spectra; i.e., the average ${ }^{1} \mathrm{H}$ NMR chemical shifts of the five- and six-membered rings $\left[\delta(5)_{\mathrm{av}} / \delta(6)_{\mathrm{av}}\right]$ of $\mathbf{3}$ [7.36/8.32] differ dramatically from those of 4 [6.66/7.55] and 5 [6.90/ 7.58] in $\mathrm{CDCl}_{3}$.

These curious differences were rationalized ${ }^{8}$ originally using Platt's perimeter model. ${ }^{11}$ In $\mathbf{4}$ and $\mathbf{5}$, two of their seven Kekulé resonance structures possess antiaromatic [16]annulene perim- eters, expected to lead to paramagnetic ring currents and consequently upfield shifts of their protons. In contrast, similar antiaromatic $[4 n] \pi$-electron ring perimeters are absent in all of the Kekulé resonance structures for 3. Additional apparent support for the perimeter interpretation was obtained by

(11) Platt, J. R. J. Chem. Phys. 1954, 22, 1448-1455. 
Table 1. Resonance Energy $\left(E_{\mathrm{res}}, \mathrm{kcal} / \mathrm{mol}\right)$ Estimated via Randic's Conjugated Circuit Model and the Semiempirical Magnetic Susceptibility Anisotropy of 1-7/8 Relative to the Benzene Value $\left(\Delta \chi_{\text {anis }}\right)$

\begin{tabular}{clll}
\hline compd & \multicolumn{1}{c}{ conjugated circuits $^{a}$} & $E_{\text {res }^{a}}$ & \multicolumn{1}{c}{$\Delta \chi_{\text {anis }^{b}}$} \\
\hline $\mathbf{1}$ & $12 R(1)+8 R(2)+6 R(3) / 6$ & 50.0 & $3.7[3.6(3.7)]$ \\
$\mathbf{2}$ & $12 R(1)+8 R(2)+6 R(3) / 6$ & 50.0 & $3.6[3.6(4.0)]$ \\
$\mathbf{3}$ & $12 R(1)+8 R(2)+6 R(3) / 6$ & 50.0 & $3.5^{c}[3.6(4.2)]$ \\
$\mathbf{4}$ & $12 R(1)+8 R(2)+6 R(3)+12 Q(4) / 7$ & 40.5 & $2.9^{c}[2.0(3.3)]$ \\
$\mathbf{5}$ & $12 R(1)+8 R(2)+6 R(3)+2 Q(3)+8 Q(4)+2 Q(5) / 7$ & $2.7^{c}[2.3(3.5)]$ & $2.1[1.5(3.1)]$ \\
$\mathbf{6}^{d}$ & $12 R(1)+8 R(2)+6 R(3)+4 Q(3)+20 Q(4)+2 Q(5) / 8$ & 32.3 & $0.8\left[0.3(2.2)^{e}\right]$ \\
\hline
\end{tabular}

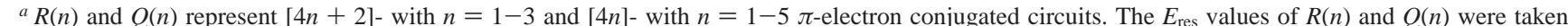
from ref $13[R(1)=20.04 ; R(2)=5.67 ; R(3)=2.31 ; Q(1)=-36.90 ; Q(2)=-10.38 ; Q(3)=-3.46 ; Q(4)=-1.38 ; Q(5)=0.00 \mathrm{kcal} / \mathrm{mol}] .{ }^{b}$ Semiempirical $\Delta \chi_{\text {anis }}$ values (see Computational Methods). In square brackets $\Delta \chi_{\text {anis }}$ in units of the benzene anisotropy calculated using ab initio CSGT-B3LYP/6-31G*// B3LYP/6-31G* (IGLO-III/RHF/6-31G*) results (see also Table 4). ${ }^{c}$ Taken from ref 12. ${ }^{d}$ See text; planar 8 is the transition state for bowl-bowl interconversion of 7. ${ }^{e}$ In the ab initio calculations the optimized bowl-shaped geometry of $\mathbf{7}$ was used (see text).

semiempirical computed magnetic susceptibility anisotropies $\Delta \chi_{\text {anis }}$ (in units of the benzene anisotropy). Although $\mathbf{3 - 5}$ are diamagnetic, $3\left(\Delta \chi_{\text {anis }}=3.5\right)$ was found to be more diamagnetic (i.e., more aromatic) than $\mathbf{4}\left(\Delta \chi_{\text {anis }}=2.9\right)$ and $\mathbf{5}\left(\Delta \chi_{\text {anis }}=2.7\right) .{ }^{12}$

However, in line with the general consensus that Platt's ring perimeter model is overly simplistic, as it ignores the effects of cyclic conjugation in smaller subunits of the $\pi$-system including those of individual rings, the situation appears to be more complicated. ${ }^{13}$ This is exemplified by the $\delta^{1} \mathrm{H}$ data of the next cyclopenta-fused pyrene congener, i.e., triscyclopenta[ $c d, f g, j k]$ pyrene (6), which recently became available. ${ }^{14}$ Its $\delta^{1} \mathrm{H}$ chemical shifts $\left[6\right.$, acetone- $\left.d_{6} ; \delta(5)_{\text {av }} / \delta(6)_{\text {av }} 6.74 / 7.44\right]$ resemble those of $\mathbf{4}$ and $\mathbf{5}$ rather than those of $\mathbf{3}$. This is significant since $\mathbf{6}$, like 3, lacks Kekulé resonance structures with antiaromatic [4n]annulene perimeters! Although the experimental data for 1-6 appear to be qualitatively reconcilable using Randić's conjugated circuit model ${ }^{13}$ or semiempirical calculated diamagnetic susceptibility anisotropies in units of benzene anisotropies $\left(\Delta \chi_{\text {anis }}\right)$, we report here that quantitatively reliable results concerning both the thermodynamic stability and aromatic character of 1-7 are only accessible at the ab initio and density functional levels of theory. The $\delta^{1} \mathrm{H}$ data calculated using the GIAO (IGLO-III) methods for 1-6 agree well with the available experimental data. It is interesting to note that the experimentally elusive tetracyclopenta[ $c d, f g, j k, m n]$ pyrene (7) is calculated to be bowlshaped and to possess the most upfield $\delta^{1} \mathrm{H}$ NMR data [GIAO (IGLO-III): $\delta(5)_{\mathrm{av}} / \delta(6)_{\mathrm{av}} 6.6(7.1) / 7.1(7.5)$ reference benzene $\delta$ $7.86(7.84) \mathrm{ppm}]$ of the series. Furthermore, it is shown that the relative thermodynamic stability of the congeners is affected by the $\sigma$-strain imposed on the pyrene skeleton by sequential cyclopenta-fusion.

\section{Computational Methods}

The effect of cyclopenta-fusion on the magnetic properties of 1-7/ 8, viz. their magnetic susceptibility anisotropies in units of the benzene anisotropy $\left(\Delta \chi_{\text {anis }}\right)$, were first calculated semiempirically with Yamaguchi and Nakajima's procedure ${ }^{15}$ (a modified London-Hoarau procedure ${ }^{16}$ using the Wheland-Mann-type approximation ${ }^{17}$ ) and planar optimized geometries.

The geometries of $\mathbf{1 - 8}$ were then optimized at the RHF/6-31G* ab initio level using GAMESS-UK ${ }^{18}$ in Utrecht and at the B3LYP/6-31G* density functional level with Gaussian $94^{19}$ in Erlangen (Figure 1). At

(12) Kataoka, M. Tetrahedron 1997, 53, 12875-12882

(13) Randić, M. Tetrahedron 1977, 33, 1905-1920 and references cited.

(14) Sarobe, M.; Havenith, R. W. A.; Jenneskens, L. W. Chem. Commun. 1999 1021-1022 and references cited.

(15) Yamaguchi, H.; Nakajima, T. Bull. Chem. Soc. Jpn. 1974, 47, 1898-1900.

(16) Hoarau, J. Ann. Chim. 1956, 1, 544-587.

(17) Wheland, G. W.; Mann, D. E. J. Chem. Phys. 1949, 17, 264-268. the B3LYP/6-31G* (RHF/6-31G*) level of theory $\mathbf{1}-\mathbf{7}$ were identified as proper minima (NIMAG $=0$ ) and $\mathbf{8}$ as a transition state [NIMAG $=1$; B3LYP/6-31G* $\left.\left(\mathrm{RHF} / 6-31 \mathrm{G}^{*}\right)-65 \mathrm{~cm}^{-1}\left(-76 \mathrm{~cm}^{-1}\right)\right]$, respectively. B3LYP/6-31G* (RHF/6-31G*) zero point energies (ZPEs) for 1-8 are reported in the table in the Supporting Information. The wave functions of 1-8 are all stable at UB3LYP/6-31G*. At the UHF/6$31 \mathrm{G}^{*}$ level of theory instabilities were found for the RHF/6-31G* wave functions of 2-6, indicating that electron correlation in these compounds appears to be important. However, the largest energy decrease was found to be $0.7 \mathrm{eV}$ for $\mathbf{2}$ with UHF natural orbital occupations of $1.80,1.63,0.37$, and 0.20 . A CASSCF $(8,9) / 6-31 \mathrm{G}$ calculation starting at the UHF/6-31G natural orbitals gave natural orbital occupations of $1.93,1.90,0.10$, and 0.05 , showing that the RHF wave function represents a good first-order approximation and that UHF exaggerates the biradical nature of the systems..$^{20}$ The good agreement between the RHF and the B3LYP density functional results further substantiates that a one-determinant description suffices for a qualitative description of these compounds. Furthermore, at the B3LYP/6-31G* (RHF/6-31G*) levels of theory the computed singlet states of 1-7 were verified to be more stable than the corresponding triplet states [see the table in the Supporting Information for $\Delta E_{\mathrm{T}-\mathrm{S}}\left(\mathrm{B} 3 \mathrm{LYP} / 6-31 \mathrm{G}^{*}\right.$ and $\mathrm{RHF} / 6-31 \mathrm{G}^{*}$ ) values].

In Utrecht, the magnetic properties of $\mathbf{1 - 7}$ [magnetic susceptibilities $\left(\chi, \mathrm{ppm}\right.$ cgs), nucleus independent chemical shifts (NICS), ${ }^{21}$ and ${ }^{1} \mathrm{H}$ NMR chemical shifts $(\delta, \mathrm{ppm})$ vs TMS $\left.\left(\sigma_{\mathrm{H}}=32.07 \mathrm{ppm}\right)\right]$ were calculated using a direct IGLO version (DIGLO) $)^{22,23}$ with the IGLOIII basis set at the RHF/6-31G* geometries. For benzene IGLO-III// RHF/6-31G* gave $\delta 7.84 \mathrm{ppm}\left(\sigma_{\mathrm{H}}=24.23 \mathrm{ppm}\right)$. In Erlangen, SCFGIAO/6-31G* ${ }^{24}$ was used to compute NICS and the $\delta^{1} \mathrm{H}$ (in ppm) vs

(18) Guest, M. F.; van Lenthe, J. H.; Kendrick, J.; Schöffel, K.; Sherwood, P.; Harrison, R. J. GAMESS-UK, a package of ab initio programs, 1998. With contributions from Amos, R. D.; Buenker, R. J.; Dupuis, M.; Handy, N. C.; Hillier, I. H.; Knowles, P. J.; Bonacic-Koutecky, V.; von Niessen, W.; Saunders, V. R.; Stone, A. J. It is derived from the original GAMESS code due to: Dupuis, M.; Spangler, D.; Wendolowski, J. NRCC Software Catalog, Vol. 1; Program No. QG01 (GAMESS), 1980.

(19) Frisch, M. J.; Trucks, G. W.; Schlegel, H. B.; Scuseri, G. E.; Robb, M. A.; Cheeseman, J. R.; Zakrzewski, V. G.; Montgomery, J. A.; Stratmann, R. E.; Burant, J. C.; Dapprich, S.; Millam, J. M.; Daniels, A. D.; Kudin, K N.; Strain, M. C.; Farkas, O.; Tomasi, J.; Barone, V.; Cossi, M.; Cammi, R.; Mennucci, B.; Pomelli, C.; Adamo, C.; Clifford, S.; Ochterski, J. Petersson, G. A.; Ayala, P. Y.; Cui, Q.; Morokuma, K.; Malick, D. K. Rabuck, A. D.; Raghavachari, K.; Foresman, J. B.; Cioslowski, J.; Ortiz, J. V.; Stefanov, B. B.; Liu, G.; Liashenko, A.; Piskorz, P.; Komaromi, I.; Gomperts, R.; Martin, R. L.; Fox, D. J.; Keith, T.; Al-Laham, M. A.; Peng, C. Y.; Nanayakkara, A.; Gonzalez, C.; Challacombe, M.; Gill, P. M. W. Johnson, B.; Chen, W.; Wong, M. W.; Andres, J. L.; Gonzalez, C.; HeadGordon, M.; Replogle, E. S.; Pople, J. A. Gaussian 94; Gaussian, Inc.: Pittsburgh, PA, 1994.

(20) Colvin, M. E.; Janssen, C. L.; Seidl, E. T.; Nielsen, I. M. B.; Melius, C. F., Chem. Phys. Lett. 1998, 287, 537-541.

(21) Schleyer, P. v. R.; Maerker, C.; Dransfeld, A.; Jiao, H.; van Eikema Hommes, N. J. R. J. Am. Chem. Soc. 1996, 118, 6317-6318. For an extensive bibliographical summary, see: Patchkovskii, S.; Thiel, W. J. Mol Model. 2000, 6, 67-75.

(22) Meier, U.; van Wüllen, C.; Schindler, M. J. Comput. Chem. 1992, 13, 551559.

(23) Fleischer, U.; Kutzelnigg, W.; Lazzeretti, P.; Mühlenkamp, V. J. Am. Chem. Soc. 1994, 116, 5298-5306. 
TMS $\left(\sigma_{\mathrm{H}}=32.78 \mathrm{ppm}\right)$, and CGST-B3LYP/6-31G*25 was used for magnetic susceptibility ( $\chi$, ppm cgs) calculations using the B3LYP/631G* geometries. For benzene SCF-GIAO/6-31G*//B3LYP/6-31G* gave $\delta 7.86\left(\sigma_{\mathrm{H}}=24.92 \mathrm{ppm}\right)$. The calculated total energies $\left(E_{\mathrm{tot}}, \mathrm{au}\right)$ and the Cartesian coordinates of the optimized geometries are given in the Supporting Information.

\section{Results and Discussion}

Conjugated Circuit Resonance Energy $\left(E_{\text {res }}\right)$ of $1-7 / 8$. In contrast to Platt's ring perimeter model, the $\delta^{1} \mathrm{H}$ anomaly of 3-6 can be resolved qualitatively using Randić's conjugated circuit model. ${ }^{13}$ Instead of considering only ring perimeter contributions, in the latter model all independent closed-shell $[4 n+2]$ and $[4 n] \pi$-electron conjugated circuits of all distinct Kekulé resonance structures are taken to contribute to the resonance energy $\left(E_{\text {res }}\right)$ of a (non)alternant PAH. ${ }^{13,26-28}$ The conjugated circuit $E_{\text {res }}$ values of $\mathbf{1 - 7 / 8}$ are summarized in Table 1 .

A survey of the possible Kekule resonance structures shows that $\mathbf{1}-\mathbf{3}$ possess only $[4 n+2] \pi$-electron conjugated circuits, while 4-7/8 contain both $[4 n+2]$ and $[4 n] \pi$-electron conjugated circuits. In line with the $\delta^{1} \mathrm{H}$ data, which are considered to reflect ring current effects, the conjugated circuit model suggests that $\mathbf{3}$ is energetically more aromatic than $\mathbf{4}$ and 5 by ca. $10 \mathrm{kcal} / \mathrm{mol}^{13}$ However, the small $E_{\text {res }}$ difference $(0.3$ $\mathrm{kcal} / \mathrm{mol}$ ) between $\mathbf{4}$ and $\mathbf{5}$ precludes a more detailed analysis of their ${ }^{1} \mathrm{H}$ NMR properties. The incorporation of a third externally fused five-membered ring in $\mathbf{6}$ leads to a further decrease of $E_{\text {res }}$ (by ca. $8 \mathrm{kcal} / \mathrm{mol}$ ); this resembles the change of $E_{\text {res }}$ in going from 3 to $\mathbf{4}$ and $\mathbf{5}$, respectively. The $E_{\text {res }}$ of 7/8 with four five-membered rings is only $22.0 \mathrm{kcal} / \mathrm{mol}$; this is a further decrease of ca. $10 \mathrm{kcal} / \mathrm{mol}$ with respect to $\mathbf{6}$. Thus for 1-6, the change of their conjugated circuit $E_{\text {res }}$ values appears to be in line with that deduced from their available $\delta^{1} \mathrm{H}$ data. However, recent results of ab initio valence bond (VB) calculations, ${ }^{29}$ in which all Kekulé resonance structures of each of the congeners $\mathbf{1 - 6}$ and $\mathbf{8}$ were explicitly taken into account, suggest that the trend predicted by the conjugated circuit model is incorrect. In contrast with the conjugated circuit $E_{\text {res }}$ values (Table 1), the ab initio VB calculations gave nearly identical resonance energies $\left[E_{\mathrm{res}}(\mathrm{VB})\right.$; range $\left.55-62 \mathrm{kcal} / \mathrm{mol}\right]$ for all members of the series. ${ }^{29}$ Thus, the agreement between the change of the conjugated circuit $E_{\text {res }}$ values and the $\delta^{1} \mathrm{H}$ data throughout the series seems to be fortuitous (see also section Ab Initio Geometries of $\mathbf{1 - 8}$ ).

Ambiguous results were also obtained using semiempirical magnetic susceptibility anisotropies relative to that of benzene ( $\left.\Delta \chi_{\text {anis }}\right)$ computed for 1-7/8 using planar Wheland-Mann-type SCF optimized geometries (see Computational Methods). The $\Delta \chi_{\text {anis }}$ values for $\mathbf{1 - 7 / 8}$ are given in Table 1 . In line with the conjugated circuit $E_{\text {res }}$ values and the $\delta^{1} \mathrm{H}$ data, $\mathbf{1}-\mathbf{3}$ have similar $\Delta \chi_{\text {anis }}$ values, but these are less negative for $\mathbf{4}$ and $\mathbf{5}$. In addition, $\Delta \chi_{\text {anis }}$ decreases even more upon introduction of additional

(24) Wolinsky, K.; Hinton, J. F.; Pulay, P. J. Am. Chem. Soc. 1990, 112, 82518260 .

(25) (a) Keith, T. A.; Bader, R. W. F. Chem. Phys. Lett. 1993, 210, 1223-231. (b) Bader, R. W. F.; Keith, T. A. Chem. Phys. Lett. 1992, 194, 1-8. (c) Bader, R. W. F.; Keith, T. A. J. Chem. Phys. 1993, 99, 3683-3693.

(26) Herndon, W. C.; Ellzey, M. L. J. J. Am. Chem. Soc. 1974, 96, 66316642.

(27) Dewar, M. J. S.; de Llano, C. J. Am. Chem. Soc. 1969, 91, 789-795.

(28) Randić, M. J. Am. Chem. Soc. 1977, 99, 444-450.

(29) Havenith, R. W. A.; van Lenthe, J. H.; Dijkstra, F.; Jenneskens, L. W. J. Phys. Chem. A. 2001, 105, 3838-3845 and references cited.
Table 2. Energy Increment Difference ( $\left.\Delta E_{\text {inc }}, \mathrm{kcal} / \mathrm{mol}\right)$ upon Incorporation of an Additional Cyclopenta-Fused Moiety of 1-7

\begin{tabular}{ccc}
\hline compd & $N_{\mathrm{CP}^{a}}$ & $\Delta E_{\text {inc }}{ }^{b}$ \\
\hline $\mathbf{1}$ & 0 & \\
$\mathbf{2}$ & 1 & $0.0(0.0)$ \\
$\mathbf{3}$ & 2 & $2.9(3.2)$ \\
$\mathbf{4}$ & 2 & $1.9(1.8)$ \\
$\mathbf{5}$ & 2 & $1.2(0.8)$ \\
$\mathbf{6}$ & 3 & $4.0(4.1)$ \\
$\mathbf{7}$ & 4 & $5.4(5.5)$ \\
\hline
\end{tabular}

${ }^{a}$ Number of externally fused cyclopenta moieties (Figure 1). ${ }^{b} \Delta E_{\text {inc }}=$ $\left[E_{\mathrm{tot}}-E_{\mathrm{tot}}(\mathbf{1})\right] / N_{\mathrm{CP}}-\left[E_{\mathrm{tot}}(\mathbf{2})-E_{\mathrm{tot}}(\mathbf{1})\right]$ at B3LYP/6-31G* (the related RHF/ $6-31 \mathrm{G}^{*}$ values are given in parentheses). For the different $E_{\text {tot }}$ values, see the table in Supporting Information.

externally fused five-membered rings. In contrast to the $\delta^{1} \mathrm{H}$ trends, the $\Delta \chi_{\text {anis }}$ values indicate that $\mathbf{4}$ (2.9) should be somewhat more aromatic than $\mathbf{5}$ (2.7).

Hence, these results show that the qualitative models do not provide clear-cut answers. Therefore, ab initio calculations were performed to gain more detailed insight in the consequences of cyclopenta-fusion, i.e., the effect of the number of cyclopenta moieties and their topology along the pyrene perimeter on their thermodynamic stability and their magnetic properties.

Ab Initio Geometries of 1-8. As shown in Figure 1, planar structures with nearly identical bond lengths and bond angles were obtained at both the B3LYP/6-31G* and RHF/6-31G* levels of theory for $\mathbf{1}\left(D_{2 h}\right), \mathbf{2}\left(C_{s}\right), \mathbf{3}\left(C_{2 v}\right), \mathbf{4}\left(C_{2 h}\right), \mathbf{5}\left(C_{2 v}\right)$, and $6\left(C_{s}\right)$. In marked contrast, the planar form of the experimentally still elusive congener tetracyclopenta[ $c d, f g, j k, m n]$ pyrene $\left(\mathbf{8}, D_{2 h}\right)$ was identified as the transition state for bowlbowl interconversion; i.e., with the bowl-shaped form $\left(\mathbf{7}, C_{2 v}\right)$ as energy minimum, the barriers are $2.9 \mathrm{kcal} / \mathrm{mol}$ at $\mathrm{B} 3 \mathrm{LYP} /$ 6-31G* and $3.8 \mathrm{kcal} / \mathrm{mol}$ at RHF/6-31G*.30

A biphenyl-like structural fragment ${ }^{31}$ is clearly discernible in 1. At B3LYP/6-31G* (RHF/6-31G*), a bond length alternation of $0.01-0.02 \AA(0.01-0.02 \AA)$ is found for the vertical six-membered rings, whereas that of the horizontal sixmembered rings is in the $0.08 \AA(0.11 \AA)$ range. Similarly, the optimized structures of $\mathbf{2 - 7}$ all possess nearly identical pyrenelike structural features at both levels of theory. The externally fused five-membered rings are all connected by $\mathrm{C}-\mathrm{C}$ bonds of ca. $1.47-1.49 \AA(1.47-1.49 \AA)$ to the pyrene framework, and in all cases they contain typical $\mathrm{C}=\mathrm{C}$ bonds with lengths of ca. 1.36-1.37 $\AA$ (1.34-1.37 $\AA$ ) (Figure 1). This large bond length alternation indicates that these five-membered rings with their largely isolated double bonds act as appendages, and may participate only in enhancing the aromaticity or perimeter delocalization (see also ref 29).

As summarized in Table 2, the energy of incorporating cyclopenta moieties (the cis $-\mathrm{HC}=\mathrm{CH}-$ increment) is not constant, but increases with increasing number of fused fivemembered rings $\left(N_{\mathrm{CP}}\right)$. Notice that these results are not affected by B3LYP/6-31G* (RHF/6-31G*) ZPE corrections. The ZPE corrections for each additional five-membered ring were found to be additive [ca. $7.3 \mathrm{kcal} / \mathrm{mol}(8.0 \mathrm{kcal} / \mathrm{mol})$ at the B3LYP/ 6-31G* (RHF/6-31G*) level of theory; see the table in the

(30) The barrier of $\mathbf{7} \rightarrow \mathbf{8}$ was also computed at the B3LYP/6-311G** (4.3 $\mathrm{kcal} / \mathrm{mol})$ and $\mathrm{MP} 2 / 6-31 \mathrm{G}^{*} / / \mathrm{RHF} / 6-31 \mathrm{G}^{*}(5.0 \mathrm{kcal} / \mathrm{mol})$ levels of theory. The results show that the barrier $\mathbf{7} \rightarrow \mathbf{8}$ is only moderately affected using different basis sets.

(31) Clar, E. Polycyclic Hydrocarbons; Academic Press Inc.: London, 1964 Single-crystal X-ray structure of 1 at 93 K: Frampton, C. S.; Knight, K. S.; Shankland, N.; Shankland, K. J. Mol. Struct. 2000, 520, 29-32. 
Chart 1. Homodesmotic Reactions of 1-7

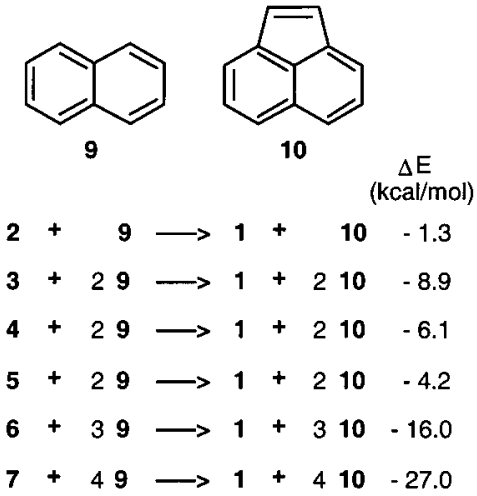

Supporting Information]. We attribute this to a progressive increase in the imposed strain on the pyrene $\sigma$-skeleton. Similar results are found using the homodesmotic reactions depicted in Chart 1. The reference reaction between 2 and naphthalene (9) furnishing $\mathbf{1}$ and acenaphthylene (10) gave a reaction energy $\Delta E$ of only $-1.3 \mathrm{kcal} / \mathrm{mol}$. Hence, the energetic effect of external cyclopenta-fusion is similar for $\mathbf{2}$ and 10. In contrast, the highly exothermic reaction energy $\Delta E$ obtained for 7 ( -27.0 $\mathrm{kcal} / \mathrm{mol}$, or ca. $-6.8 \mathrm{kcal} / \mathrm{mol}$ per fused five-membered ring) reveals that consecutive addition of cyclopenta moieties indeed imposes increasingly severe strain on the pyrene $\sigma$-skeleton.

This interpretation is further supported by the aromatic stabilization energies ( $\mathrm{ASE}_{\mathrm{isom}}$ ) calculated for $\mathbf{1 - 7}$ and related systems (Chart 2 and Table 4). In these calculations, the $\mathrm{ASE}_{\mathrm{isom}}$ is defined as the energy difference between the methylsubstituted derivative $(\mathbf{1 a}-\mathbf{7 a})$ and its quinoid isomer containing an exo-methylene substituent $(\mathbf{1 b}-\mathbf{7 b})$. This isodesmic isomerization energy method has the advantage of simplicity; only one closely related reference compound is needed, and this should compensate for strain very roughly. ${ }^{32}$ Throughout the whole series, the moderately varying $\mathrm{ASE}_{\text {isom values suggest }}$ that all congeners indeed possess similar $\pi$-electron delocalization energies in line with the $E_{\text {res }}(\mathrm{VB})$ values obtained using ab initio VB calculations. ${ }^{29}$ Consequently, the changes in overall stability [total energies $\left(E_{\mathrm{tot}}\right)$ ] have to be attributed to strain imposed on the $\sigma$-skeleton of the pyrene framework. This interpretation is at variance with the conclusions obtained using the conjugated circuit $E_{\text {res }}$ values [Table 1 and see section Conjugated Circuit Resonance Energy $\left(E_{\text {res }}\right)$ of 1-7/8].

As shown in Table 3, the thermodynamic stability order [based on the total energies $\left.\left(E_{\mathrm{tot}}\right)\right], \mathbf{5}>\mathbf{4}>\mathbf{3}$, is noteworthy. It deviates from the aromaticity order, $\mathbf{3}>\mathbf{4} \sim \mathbf{5}$, based on the conjugated circuit $E_{\text {res }}$ values (Table 1) and on the magnetic properties $\left(\mathbf{3}>\mathbf{5}>\mathbf{4} ; \delta^{1} \mathrm{H}, \Delta \chi_{\text {anis }}, \chi_{\text {tot }}, \sum\right.$ NICS, $\Lambda$, Tables 1 and 4 , vide infra). Since $\mathbf{3} \mathbf{- 5}$ possess similar ZPEs [B3LYP/ 6-31G* (RHF/6-31G*): 3, $145.16 \mathrm{kcal} / \mathrm{mol}(155.6 \mathrm{kcal} / \mathrm{mol})$; 4, $145.15 \mathrm{kcal} / \mathrm{mol}(155.6 \mathrm{kcal} / \mathrm{mol})$; and 5, $145.19 \mathrm{kcal} / \mathrm{mol}$ $(155.7 \mathrm{kcal} / \mathrm{mol})$; see the table in the Supporting Information], the thermodynamic stability order will not be affected by inclusion of ZPE corrections. Thus, 3 has the highest aromatic character (magnetic properties), but is the least stable isomer. This reverse relationship has also been found in other systems, e.g., [5,5]-, [5,6]-, [5,7]- and [6,7]-fused bicyclic systems as well; 33 the most stable representative of isomeric nonalternant polycyclic aromatic compounds need not be the most aromatic!

(32) Wakita, K.; Tokitoh, N.; Okazaki, R.; Nagase, S.; Schleyer, P. v. R.; Jiao, H. J. Am. Chem. Soc. 1999, 121, 11336-11344.
Chart 2. Aromatic Stabilization Energies ( $A \mathrm{SE}_{\mathrm{Isom}}, \mathrm{kcal} / \mathrm{mol}$, B3LYP/6-31G*//Fopt) and Difference in Diamagnetic Susceptibilities Taken as the Diamagnetic Susceptibility Exaltations $(\Lambda, \mathrm{ppm}$ cgs) at the CSGT-B3LYP/6-31G*//B3LYP/ 6-31G* Level ${ }^{a}$

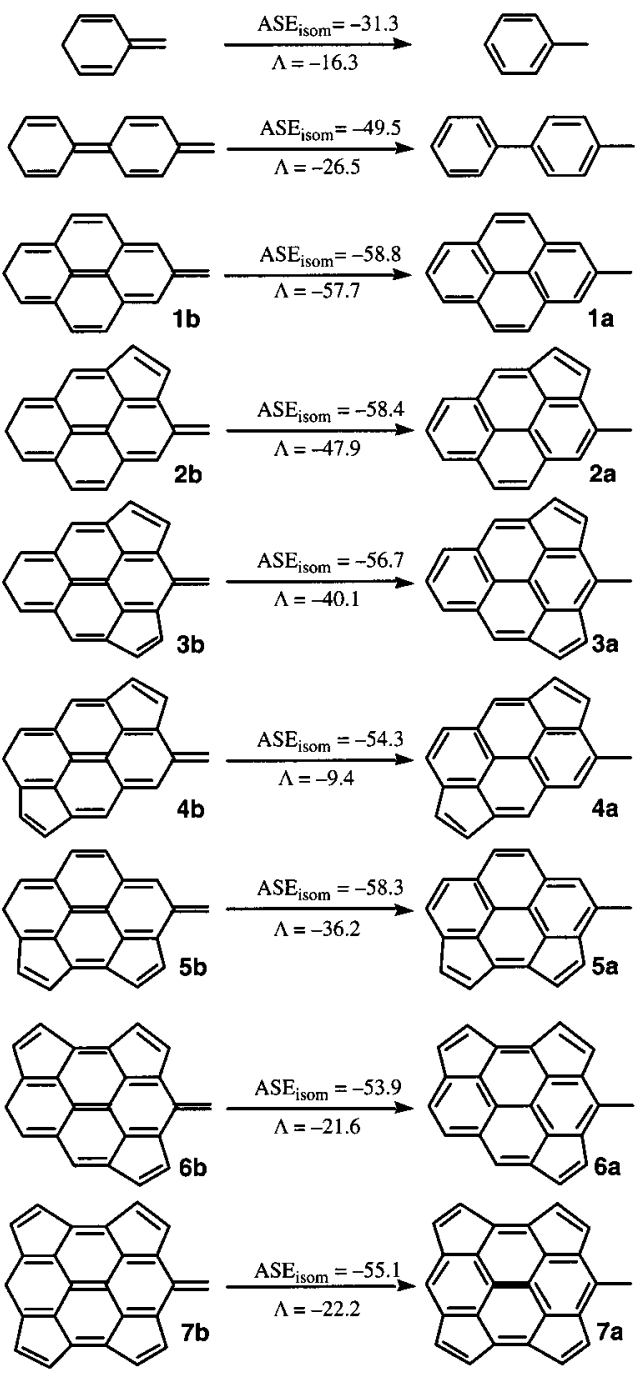

${ }^{a}$ For Cartesian coordinates of the optimized geometries of $\mathbf{1 a}-\mathbf{7 a}$ and $\mathbf{1 b}-\mathbf{7 b}$, see Supporting Information.

Table 3. RHF/6-31G* Relative Energies ( $\left.E_{\text {rel }}, \mathrm{kcal} / \mathrm{mol}\right)$ for 3-5 and for the "Distorted" Cyclopenta[co] pyrene Models $\left(3 \mathrm{H}_{2}-5 \mathrm{H}_{2}\right.$; Figure 2 and Supporting Information)

\begin{tabular}{cccc}
\hline compd & $E_{\text {rel }}{ }^{a}$ & model $^{b}$ & $E_{\text {rel }}^{b}$ \\
\hline $\mathbf{3}$ & $4.8(3.4)$ & $\mathbf{3 H}_{2}$ & 5.2 \\
$\mathbf{4}$ & $1.9(1.5)$ & $\mathbf{4 H}_{2}$ & 1.7 \\
$\mathbf{5}$ & $0.0(0.0)$ & $\mathbf{5 H}$ & 0.0 \\
\hline
\end{tabular}

${ }^{a} \mathrm{~B} 3 \mathrm{LYP} / 6-31 \mathrm{G}^{*}$ values in parentheses. ${ }^{b}$ See text.

To explain this apparent anomaly, RHF/6-31G* single-point energies were also computed on "distorted" cyclopenta $[c d]-$ pyrene models (designated $\mathbf{3} \mathrm{H}_{2}, \mathbf{4} \mathrm{H}_{2}$, and $\mathbf{5} \mathrm{H}_{2}$; see Figure 2, Table 3, and Supporting Information), derived from $\mathbf{3}-\mathbf{5}$ by replacing one of the equivalent five-membered rings of 3-5 by two carbon-hydrogen bonds $(1.074 \AA$ ) having the same

(33) (a) Subramanian, G.; Schleyer, P. v. R.; Jiao, H. Organometallics 1997, 16, 2362-2369. (b) Subramanian, G.; Schleyer, P. v. R.; Jiao, H. Angew. Chem. 1996, 108, 2824-2827; Angew. Chem., Int. Ed. Engl. 1996, 35, 2638-2641. (c) Schleyer, P. v. R.; Najafian, K.; Mebel, A. Inorg. Chem. 1998, 37, 6765-6772. 
Table 4. Computed Magnetic Properties of 1-7

\begin{tabular}{|c|c|c|c|c|c|c|c|}
\hline & 1 & 2 & 3 & 4 & 5 & 6 & 7 \\
\hline$\chi_{\text {out}- \text { of }- \text { plane }}{ }^{a}$ & $\begin{array}{c}-305.2 \\
(-331.6)\end{array}$ & $\begin{array}{c}-308.5 \\
(-357.8)\end{array}$ & $\begin{array}{c}-316.9 \\
(-383.8)\end{array}$ & $\begin{array}{c}-211.6 \\
(-321.9)\end{array}$ & $\begin{array}{c}-224.3 \\
(-333.1)\end{array}$ & $\begin{array}{c}-174.8 \\
(-315.6)\end{array}$ & $\begin{array}{c}-109.0 \\
(-273.2)\end{array}$ \\
\hline$\chi_{\text {in-plane av }}{ }^{a}$ & $\begin{array}{c}-51.8 \\
(-85.3)\end{array}$ & $\begin{array}{c}-57.5 \\
(-92.9)\end{array}$ & $\begin{array}{c}-63.1 \\
(-100.3)\end{array}$ & $\begin{array}{c}-63.5 \\
(-100.4)\end{array}$ & $\begin{array}{c}-63.1 \\
(-100.6)\end{array}$ & $\begin{array}{c}-69.0 \\
(-107.9)\end{array}$ & $\begin{array}{c}-84.9 \\
(-124.0)\end{array}$ \\
\hline$\chi_{\text {anis }}{ }^{a, b}$ & $\begin{array}{l}-253.4 \\
(-246.3)\end{array}$ & $\begin{array}{l}-251.0 \\
(-264.9)\end{array}$ & $\begin{array}{l}-253.8 \\
(-283.5)\end{array}$ & $\begin{array}{l}-148.1 \\
(-221.5)\end{array}$ & $\begin{array}{l}-161.2 \\
(-232.6)\end{array}$ & $\begin{array}{l}-105.8 \\
(-207.7)\end{array}$ & $\begin{array}{c}-24.1 \\
(-149.2)\end{array}$ \\
\hline$\chi_{\mathrm{tot}^{a}}^{a}$ & $\begin{array}{l}-136.3 \\
(-167.4)\end{array}$ & $\begin{array}{l}-141.2 \\
(-181.2)\end{array}$ & $\begin{array}{l}-147.7 \\
(-194.8)\end{array}$ & $\begin{array}{l}-112.9 \\
(-174.3)\end{array}$ & $\begin{array}{l}-116.8 \\
(-178.1)\end{array}$ & $\begin{array}{l}-104.3 \\
(-177.1)\end{array}$ & $\begin{array}{c}-92.9 \\
(-173.7)\end{array}$ \\
\hline$\Delta \chi_{\text {anis }}{ }^{a, c}$ & $\begin{array}{c}3.6 \\
\text { (3.7) }\end{array}$ & $\begin{array}{c}3.6 \\
(4.0)\end{array}$ & $\begin{array}{c}3.6 \\
(4.2)\end{array}$ & $\begin{array}{c}2.0 \\
(3.3)\end{array}$ & $\begin{array}{c}2.3 \\
(3.5)\end{array}$ & $\begin{array}{c}1.5 \\
(3.1)\end{array}$ & $\begin{array}{c}0.3 \\
(2.2)\end{array}$ \\
\hline$\sum \operatorname{NICS}(1.0)^{d}$ & $\begin{array}{l}-48.4 \\
(-41.2)\end{array}$ & $\begin{array}{l}-43.4 \\
(-37.9)\end{array}$ & $\begin{array}{l}-44.7 \\
(-35.1)\end{array}$ & $\begin{array}{l}-25.8 \\
(-22.0)\end{array}$ & $\begin{array}{l}-27.4 \\
(-23.7)\end{array}$ & $\begin{array}{l}-15.4 \\
(-12.6)\end{array}$ & $\begin{array}{l}-19.0^{f / 3} .4 g \\
\left(-17.4^{f} / 7.6^{g}\right)\end{array}$ \\
\hline$\delta(6)_{\mathrm{av}}{ }^{d}$ & $\begin{array}{c}8.6 \\
(8.7)\end{array}$ & $\begin{array}{c}8.6 \\
(8.8)\end{array}$ & $\begin{array}{c}8.7 \\
(8.9)\end{array}$ & $\begin{array}{c}8.0 \\
(8.3)\end{array}$ & $\begin{array}{c}8.0 \\
(8.3)\end{array}$ & $\begin{array}{c}7.7 \\
(8.0)\end{array}$ & $\begin{array}{c}7.1 \\
(7.5)\end{array}$ \\
\hline & 8.1 & 8.2 & 8.3 & 7.6 & 7.6 & 7.4 & \\
\hline$\delta(5)_{\mathrm{av}}{ }^{d}$ & & $\begin{array}{c}7.7 \\
(7.9) \\
73\end{array}$ & $\begin{array}{c}7.7 \\
(7.9) \\
74\end{array}$ & $\begin{array}{c}7.1 \\
(7.4) \\
67\end{array}$ & $\begin{array}{c}7.3 \\
(7.6) \\
69\end{array}$ & $\begin{array}{c}7.0 \\
(7.4) \\
67\end{array}$ & $\begin{array}{c}6.6 \\
(7.1)\end{array}$ \\
\hline $\mathrm{ASE}_{\mathrm{isom}^{e}}$ & $\begin{array}{l}-58.8 \\
(-58.6)\end{array}$ & $\begin{array}{l}-58.4 \\
(-58.1)\end{array}$ & $\begin{array}{c}1.4 \\
-56.7 \\
(-56.7)\end{array}$ & $\begin{array}{c}0.7 \\
-54.3 \\
(-55.6)\end{array}$ & $\begin{array}{r}0.9 \\
-58.3 \\
(-57.7)\end{array}$ & $\begin{array}{c}0.7 \\
-53.9 \\
(-56.0)\end{array}$ & -55.1 \\
\hline
\end{tabular}

${ }^{a}$ In ppm cgs at CSGT-B3LYP/6-31G*//B3LYP/6-31G*, IGLO-III//RHF/6-31G* values in parentheses: CSGT $\left(\right.$ IGLO-III), $\chi_{\text {in }- \text { plane av }}=\left(\chi_{x x}+\chi_{y y}\right) / 2$ $\chi_{\text {tot }}\left(\right.$ benzene), -46.1 (-61.5); $\chi_{\text {out }- \text { of }- \text { plane }}($ benzene $),-92.6(-106.1) ; \chi_{\text {in }- \text { plane av }}($ benzene $),-22.8(-39.2) ; \chi_{\text {anis }}($ benzene $),-69.8(-66.9)$ ppm cgs. NICS [GIAO (IGLO-III)]: $-11.6(-10.0)$ at $0.0 \AA ;-13.3(-11.6)$ at $0.5 \AA ;-12.8(-11.3)$ ppm at $1.0 \AA$ over the ring center. ${ }^{b} \Delta \chi_{\text {anis }}=\chi_{\text {out }- \text { of }- \text { plane }}-\chi_{\text {in-plane av. }}$. ${ }^{c}$ Magnetic susceptibility anisotropy in units of the benzene anisotropy ( $\left.\Delta \chi_{\text {anis }}\right)$ using GIAO [(IGLO-III), see also Table 1 and the Supporting Information]. ${ }^{d} \mathrm{In} \mathrm{ppm}$ at SCF-GIAO/6-31G*//B3LYP/6-31G*, IGLO-III/RHF/6-31G* values in parentheses and the experimental values, in italics $\left[\delta(5)_{\mathrm{av}} / \delta(6)_{\mathrm{av}}: 3\right.$ (7.36/8.32), 4 (6.66/7.55), and 5 (6.90/7.58), ${ }^{6,8}$ and $\left.\mathbf{6}(6.74 / 7.44)^{14}\right]$. For benzene SCF-GIAO/6-31G*//B3LYP/6-31G* (IGLO-III/RHF/6-31G*) gave $\delta$ 7.86 (7.84) ppm (all values are referenced to TMS at $0.00 \mathrm{ppm}$; see Computational Methods). The NICS(1.0) values are computed at points 1.0 A above the center of individual rings, and $\sum$ NICS(1.0) is the sum of the individual rings (see also Chart 3 and Supporting Information). ${ }^{e}$ Aromatic stabilization energies (ASE ${ }_{\text {isom }}, \mathrm{kcal} / \mathrm{mol}$; see text and Chart 2). IGLO-III//RHF/6-31G* values in parentheses. ${ }^{f}$ Concave side (see Chart 3; "i"). ${ }^{g}$ Convex side (see Chart 3; "o").

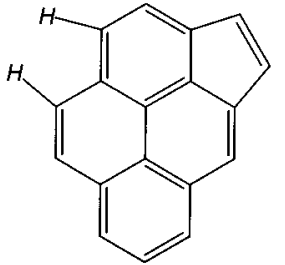

$3 \mathrm{H}_{2}$

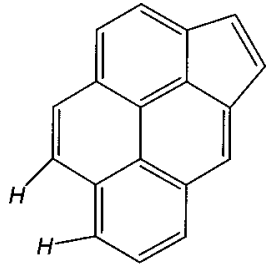

$4 \mathrm{H}_{2}$

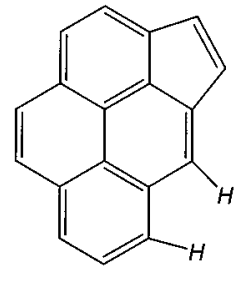

$\mathbf{5} \mathrm{H}_{2}$
Figure 2. The "distorted" cyclopenta $[c d]$ pyrene models $3 \mathrm{H}_{2}, \mathbf{4} \mathrm{H}_{2}$, and $\mathbf{5} \mathrm{H}_{2}$. See the Supporting Information for Cartesian coordinates of the partially optimized geometries and see the text.

valence angles as those in the five-membered rings (see Figure 1). Since both 2 and its "distorted" analogues $\left(3 \mathrm{H}_{2}, 4 \mathrm{H}_{2}\right.$, and $\mathbf{5} \mathrm{H}_{2}$ ) have identical $\pi$-orbital systems, this enables the assessment of $\sigma$-strain contributions in the pyrene skeleton imposed by the dicyclopenta-fusion topology. Both the stability order (qualitatively) and the energy differences (quantitatively) of the "distorted" cyclopenta[cd]pyrene models $\left(3 \mathrm{H}_{2}, \mathbf{4} \mathrm{H}_{2}\right.$, and $\left.5 \mathrm{H}_{2}\right)$ agree excellently with those of $\mathbf{3 - 5}(\mathbf{5}>\mathbf{4}>\mathbf{3}$, Table 3$)$. Hence, $\sigma$-strain imposed on the pyrene skeleton by the dicyclopenta-fusion indeed appears to dominate the relative stability order of 3-5. This provides an explanation for the fact that all attempts to synthesize the experimentally elusive tetracyclopenta $[c d, f g, j k, m n]$ pyrene (7) following procedures similar to those used for $\mathbf{2}-\mathbf{6}^{3,6-9,14}$ still remain unsuccessful. ${ }^{5}$

Magnetic Properties of 1-7. While all the computed $\delta^{1} \mathrm{H}$ values $\left[\delta(6)_{\mathrm{av}}\right.$ and $\left.\delta(5)_{\mathrm{av}}\right]$ are downfield with respect to the experimental chemical shifts, it is gratifying that the differences are nearly constant and that the order is the same (Table 4). Moreover, both GIAO and IGLO-III methods reproduce the experimental changes of the $\delta^{1} \mathrm{H}$ data in the series $\mathbf{1 - 6}$ in considerable detail. Compared to the available experimental data for $\mathbf{1 - 6}$, the computed ${ }^{1} \mathrm{H}$ NMR chemical shifts are overestimated by $0.3-0.5 \mathrm{ppm}$ at the SCF-GIAO/6-31G*//B3LYP/6-
31G level (IGLO-III//RHF/6-31G* level: $0.6-0.7 \mathrm{ppm}$ ), and the same is also found for benzene [GIAO (IGLO-III) $\delta 7.86$ (7.84) ppm]. Taking this difference into account, the estimated $\delta^{1} \mathrm{H}$ data for 7, viz. $\delta(6)_{\mathrm{av}}$ of ca. $6.7 \mathrm{ppm}$ (IGLO-III: ca. 6.8 ppm) and $\delta(5)_{\mathrm{av}}$ of ca. $6.2 \mathrm{ppm}$ (IGLO-III: ca. $\left.6.4 \mathrm{ppm}\right)$, should be reliable.

The fusion of one five-membered ring onto the pyrene skeleton (2) does not affect the $\delta^{1} \mathrm{H}, \chi_{\text {anis }}$, or $\mathrm{ASE}_{\text {isom, but the }}$ NICS[1.0 (0.0)] values are reduced in magnitude by about 1 ppm (Chart 3). The five-membered ring has a slightly positive NICS value. Note that the NICS values of the six-membered rings, next to a five-membered ring, are slightly less negative than those without the five-membered ring.

In going from $\mathbf{3}$ to $\mathbf{4}$ and finally $\mathbf{5}$, the $\chi_{\text {tot }}$ values become less negative, indicating a diminished magnetic aromatic character in the $\mathbf{3}>\mathbf{5}>\mathbf{4}$ order. It is possible to compare isomers 3-5 directly, since they have nearly the same ring area. The in-plane susceptibility anisotropies $\left(\chi_{\text {in-plane av }}\right)$ of $\mathbf{3 - 5}$ are nearly identical, but their out-of-plane $\left(\chi_{\text {out-of-plane }}\right)$ values change significantly. Hence, the changes in aromaticity can be ascribed primarily to variations in the $\pi$-systems. This is in line with the observed changes of their ${ }^{1} \mathrm{H}$ NMR properties and reflects that the induced ring currents in the series 3-5 differ. It is noteworthy that a comparison between the semiempirical $\Delta \chi_{\text {anis }}$ values and those computed using the ab initio GIAO (IGLO-III) results reveal that in contrast to the semiempirical results $\left(\Delta \chi_{\text {anis }} \mathbf{3}>\mathbf{4} \sim \mathbf{5}\right)$ the ab initio $\Delta \chi_{\text {anis }}$ results predict the proper order $\mathbf{3}>\mathbf{5}>\mathbf{4}$ (Tables 1 and 4 ). Notwithstanding, also at the ab initio level the difference between $\Delta \chi_{\text {anis }}$ for 4 and $\mathbf{5}$ is very small. The aromaticity order of $\mathbf{3}-\mathbf{5}$ also can be deduced from the estimated diamagnetic susceptibility exaltation ( $\Lambda$, ppm cgs) derived from the equations in Chart 2. On this basis, $\mathbf{3 b} \rightarrow \mathbf{3 a}(\Lambda=-40.1 \mathrm{ppm}$ cgs $)$ is the most, while $\mathbf{4 b} \rightarrow$ 4a $(\Lambda=-9.4$ ppm cgs $)$ is the least aromatic. As expected, this 
Chart 3. NICS for Five- and Six-Membered Rings at $1.0 \AA$ above the Ring Centers ${ }^{a}$

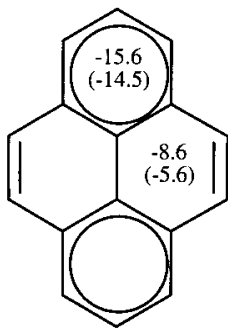

$1\left(D_{2 h}\right)$

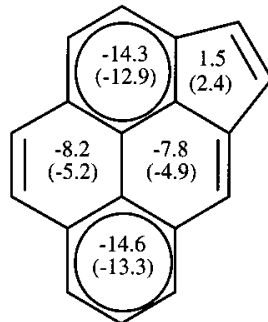

$2\left(C_{\mathrm{s}}\right)$

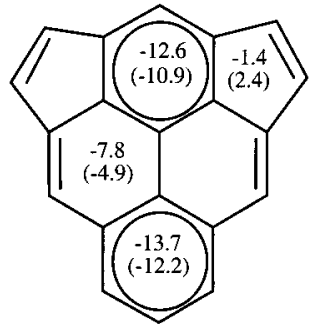

$3\left(C_{2 v}\right)$

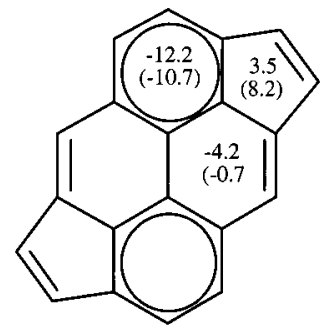

$4\left(C_{2 h}\right)$

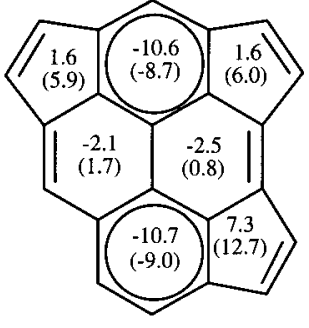

$6\left(C_{\mathrm{s}}\right)$

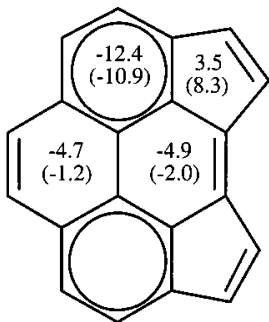

$5\left(C_{2 v}\right)$

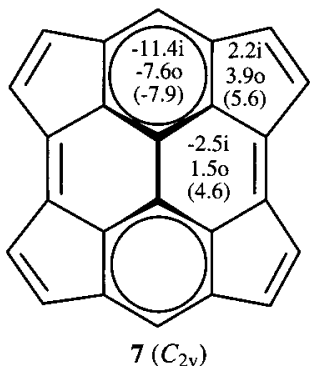

$7\left(C_{2 v}\right)$
${ }^{a}$ The values at the ring center $(0.0 \AA)$ are given in parentheses for comparison (ppm, SCF-GIAO/6-31G*//B3LYP/6-31G*). For 7, the values ("i") are inside the bowl (concave side) and ("o") outside (convex side) the bowl.

order is also supported by the sum of the NICS values of the individual rings at $1.0 \AA$ over their centers $\left[\sum\right.$ NICS(1.0), Table 4]. With the exception of the exaltation value $\Lambda$ for the conversion of $\mathbf{4 b} \rightarrow \mathbf{4 a},{ }^{34}$ IGLO-III//RHF/6-31G* calculations gave similar results and trends for various isodesmic reactions depicted in Chart $2\left(\mathbf{1 b} \rightarrow \mathbf{1 a}, \mathrm{ASE}_{\text {isom }}-58.6 \mathrm{kcal} / \mathrm{mol}\right.$ and $\Lambda$ $-54.7 \mathrm{ppm}$ cgs; $\mathbf{2 b} \rightarrow \mathbf{2 a}, \mathrm{ASE}_{\mathrm{isom}}-58.1 \mathrm{kcal} / \mathrm{mol}$ and $\Lambda-49.7$ $\mathrm{ppm} \mathrm{cgs} ; \mathbf{3 b} \rightarrow \mathbf{3 a}, \mathrm{ASE}_{\mathrm{isom}}-56.7 \mathrm{kcal} / \mathrm{mol}$ and $\Lambda-45.2 \mathrm{ppm}$ cgs; $4 \mathbf{b} \rightarrow \mathbf{4 a}, \mathrm{ASE}_{\text {isom }}-55.6 \mathrm{kcal} / \mathrm{mol}$ and $\Lambda-27.2 \mathrm{ppm} \mathrm{cgs}$; $\mathbf{5 b} \rightarrow \mathbf{5 a}, \mathrm{ASE}_{\mathrm{isom}}-57.7 \mathrm{kcal} / \mathrm{mol}$ and $\Lambda-40.6 \mathrm{ppm} \mathrm{cgs;} \mathrm{and}$ $\mathbf{6 b} \rightarrow 6 \mathbf{6 a}, \mathrm{ASE}_{\text {isom }}-56.0 \mathrm{kcal} / \mathrm{mol}$ and $\left.\Lambda-24.6 \mathrm{ppm} \mathrm{cgs}\right)$.

More details are obtained from the individual six- and fivemembered ring NICS values (Chart 3). For example, the two biphenyl-type six-membered rings (shown vertically in Chart 3 ) in 3-5 have nearly the same NICS[1.0 (0.0)] values, and therefore they are nearly equally aromatic. However, the NICS-

(34) The discrepancy between the $\Lambda$ value for $\mathbf{4 b} \rightarrow \mathbf{b a}$ (CGST-B3LYP/6-31G*// B3LYP/6-31G* $-9.4 \mathrm{ppm}$ cgs and IGLO-III//RHF/6-31G* $-27.2 \mathrm{ppm} \mathrm{cgs}$ ) could be traced to the use of the hybrid density functional method. Recalculation of $\Lambda$ for $\mathbf{4 b} \rightarrow \mathbf{4 a}$ at the CSGT-RHF/6-31G*//B3LYP/6 $31 \mathrm{G}^{*}$ level of theory gave $-26.3 \mathrm{ppm}$ cgs in agreement with the IGLOIII//RHF/6-31G* result. The computed CSGT-RHF/6-31G*//B3LYP/6$31 \mathrm{G}^{*}$ and IGLO-III//RHF/6-31G* $\chi_{\text {tot }}$ values were 119.1 and $146.5 \mathrm{ppm}$ cgs for $\mathbf{4 a}$, and 109.7 and 120.2 ppm cgs for $\mathbf{4 b}$, respectively. Remarkably, however, both CGST-B3LYP/6-31G*//B3LYP/6-31G* and IGLO-III/RHF/ 6-31G* gave nearly identical $\Lambda$ values for $\boldsymbol{x} \boldsymbol{b} \rightarrow \boldsymbol{x} \boldsymbol{a}$ for $\boldsymbol{x}$ being $\mathbf{1}-\mathbf{3}, \mathbf{5}$, and 6 (see text and Chart 2).
[1.0 (0.0)] values of the two horizontal six-membered rings of $3[-7.8(-4.9) \mathrm{ppm}]$ are more negative than those of $4[-4.2$ $(-0.7) \mathrm{ppm}]$ and 5 [-4.7/-4.9 (-1.2/-2.0) ppm], which can be considered as close to nonaromatic. Significant changes are found for the five-membered rings $[3,-1.4$ (2.4) ppm (nonaromatic); 4, 3.5 (8.2) ppm (antiaromatic); and 5, 3.5 (8.3) ppm (antiaromatic)].

For 6, the NICS[1.0 (0.0)] values show that its three fused five-membered rings decrease the aromaticity of the central sixmembered rings further. The five-membered rings are all antiaromatic; the largest NICS[1.0 (0.0)] value is 7.3 (12.7) ppm. The elimination of aromaticity in $\mathbf{6}$ is not only supported by NICS, but also by the $\delta^{1} \mathrm{H}, \chi_{\text {anis, }}$, and $\chi_{\text {tot }}$ data. Note that the $\chi_{\text {in-plane av }}$ contribution of $\mathbf{6}$ is close to those of $\mathbf{3 - 5}$. Hence all the changes in aromaticity going from $3-5$ to 6 are from the $\pi$-systems, as a consequence of a different induced ring current mode due to triscyclopenta-fusion.

The ring protons of the experimentally elusive congener $\mathbf{7}$, with four externally fused five-membered rings, are calculated to be even more upfield shifted, and very strongly decreased aromaticity is expected on the basis of its magnetic properties. More details are shown by the NICS data for the five- and sixmembered rings (Chart 3). Remarkably, the sum of the NICS(1.0) values of 7 is positive (3.4 ppm) rather than negative on the convex side [ $\sum \mathrm{NICS}(1.0)$ concave side $-19.0 \mathrm{ppm}$ ]. Also for $\sum$ NICS(0.0) a positive value $(15.8 \mathrm{ppm})$ is found (Table 4); IGLO-III//RHF/6-31G* gave similar trends [ $2 \mathrm{NICS}(1.0)$ convex side $7.6 \mathrm{ppm}$ and concave side $-17.4 \mathrm{ppm}$, Table 4 and $\sum$ NICS(0.0) $24.8 \mathrm{ppm}$; see the chart in the Supporting Information].

\section{Conclusions}

For $\mathbf{1}-6$ and $\mathbf{7 / 8}$ the magnetic susceptibility anisotropies in units of benzene anisotropies $\left(\Delta \chi_{\text {anis }}\right)$ calculated using Yamaguchi and Nakajima's procedure ${ }^{15}$ (a modified London-Hoarau procedure $^{16}$ using the Wheland-Mann-type approximation ${ }^{17}$ ) are inconsistent with the available $\delta^{1} \mathrm{H}$ NMR data. This is demonstrated for the isomeric dicyclopenta-fused pyrenes $\mathbf{3}-\mathbf{5}$. The conjugated circuit $E_{\text {res }}$ values $(\mathbf{3}>\mathbf{4} \sim \mathbf{5})$ and the semiempirical $\Delta \chi_{\text {anis }}$ results $(\mathbf{3}>\mathbf{4} \sim \mathbf{5})^{12}$ suggest that $\mathbf{3}$ is the most aromatic isomer and, hence, should have the lowest energy, viz. highest thermodynamic stability.

However, an unexpected stability order of these isomers (5 $>4>3$ ) has been found at both the ab initio (RHF/6-31G*) and density functional (B3LYP/6-31G*) levels of theory. This stability order, which deviates from the order found using the magnetic criteria $(\mathbf{3}>\mathbf{5}>\mathbf{4})$, is attributed to $\sigma$-strain imposed on the pyrene skeleton from the externally fused five-membered rings. Both homodesmotic reaction energies (Chart 1) and the

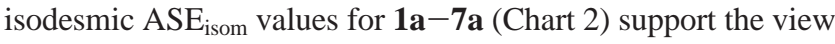
that $\sigma$-strain increases concomitant with an increasing number of externally fused five-membered rings. This provides a rationalization for the facts that $\mathbf{6}$ is only accessible in moderately yield using $\mathrm{FVT}^{14}$ and that hitherto 7 still remains the experimentally elusive congener. ${ }^{5}$

Quantitatively reliable results are obtained using ab initio GIAO and IGLO-III calculations for pyrene (1) and its cyclopenta-fused derivatives $\mathbf{2 - 6}$, for which experimental data are available. The results show that the number of cyclopenta moieties as well as cyclopenta-fusion topology (3-5) indeed markedly affects their aromaticity and their relative thermody- 
namic stability. In line with the changes of the gross ${ }^{1} \mathrm{H}$ NMR spectroscopic features of $\mathbf{3} \mathbf{- 5}$, their aromatic character according to the magnetic criteria decreases in the order $\mathbf{3}>\mathbf{5}>\mathbf{4}$. Furthermore, introduction of additional cyclopenta moieties, viz. 6 and 7, leads to a further reduction of their aromatic character.

Acknowledgment. Financial support for M.S., Basque Governement [Beca de Formacion de Investigadores (Utrecht)], the U.S. Department of Energy (Boston), and the Deutsche Forschungsgemeinschaft (Erlangen) are gratefully acknowledged.

Supporting Information Available: Total energies $\left(E_{\mathrm{tot}}, \mathrm{au}\right.$; B3LYP/6-31G* and RHF/6-31G*) of $\mathbf{1 - 1 0}$ and benzene, singlet-triplet energy gap $\left(\Delta E_{\mathrm{T}-\mathrm{S}}, \mathrm{kcal} / \mathrm{mol}\right.$; B3LYP/6-31G* and $\mathrm{RHF} / 6-31 \mathrm{G}^{*}$ ) of $\mathbf{1 - 7}$, and zero point energies (ZPE, kcal/ mol; RHF/6-31G*) of 1-8. Cartesian coordinates of B3LYP/ 6-31G* and RHF/6-31G* optimized geometries of compounds $\mathbf{1 - 8}$, the "distorted" cyclopenta $[c d]$ pyrenes $\mathbf{3} \mathrm{H}_{2}-\mathbf{5} \mathrm{H}_{2},(\mathrm{RHF} /$ 6-31G*), the reference compounds 1a-7a (B3LYP/6-31G*) and 1b-7b (B3LYP/6-31G*) in Chart 2 and a duplicate of Chart 3 containing IGLO-III//RHF/6-31G* NICS [1.0 (0.0)] values. (PDF) This material is available free of charge via the Internet at http://pubs.acs.org.

JA011538N 